\title{
Agonistic Anti-CD40 Monoclonal Antibody ADC-1013
}

National Cancer Institute

\section{Source}

National Cancer Institute. Agonistic Anti-CD40 Monoclonal Antibody ADC-1013. NCI

Thesaurus. Code C121538.

\begin{abstract}
A human immunoglobulin (Ig) G1 monoclonal antibody directed ag ainst the cell surface receptor CD40 with potential immunostimulatory and antineoplastic activities. Upon intratumoral administration, agonistic anti-CD40 monoclonal antibody ADC-1013 binds to CD40 on antigen-presenting dendritic cells, which leads to the activation and proliferation of effector and memory T-cells, and enhances the immune response against tumor cells. In addition, this agent binds to the CD40 antigen present on the surfaces of tumor cells, which induces antibody-dependent cytotoxicity (ADCC). This eventually inhibits the proliferation of CD40-expressing tumor cells. CD40, a stimulatory receptor and a member of the tumor necrosis factor (TNF) receptor superfamily, is expressed on various immune cells, such as macrophages, dendritic cells and various tumor cell types; it plays a key role in the activation of the immune system.
\end{abstract}

